\title{
Identification of Novel Bioactive Hexapeptides Against Phytopathogenic Bacteria Through Rapid Screening of a Synthetic Combinatorial Library
}

\author{
Choi, Jaehyuk ${ }^{1}$ and Eunpyo Moon ${ }^{2 *}$ \\ ${ }^{1}$ Department of Molecular Science and Technology and ${ }^{2}$ Department of Biological Sciences, Ajou University, Suwon 442-749, Korea
}

Received: September 1, 2008 / Revised: December 31, 2008 / Accepted: March 4, 2009

\begin{abstract}
Antimicrobial peptides (AMPs) are considered to be a promising alternative to conventional antibiotics for future generations. We identified four novel hexapeptides with antimicrobial activity: KCM11 (TWWRWW-NH $)$, KCM12 (KWRWIW-NH ${ }_{2}$ ), KCM21 (KWWWRW-NH $)$, and KRS22 (WRWFIH-NH ) , through positional scanning of a synthetic peptide combinatorial library (PS-SCL). The ability of these peptides to inhibit the growth of a variety of bacteria and unicellular fungi was evaluated. KCM11 and KRS22 preferentially inhibited the normal growth of fungal strains, whereas KCM12 and KCM21 were more active against bacterial strains. Bactericidal activity was addressed in a clear zone assay against phytopathogenic bacteria, including Pectobacterium spp., Xanthomonas spp., Pseudomonas spp., etc. KCM21 showed the highest activity and was effective against a wide range of target organisms. Application of KCM21 with inoculation of Pectobacterium carotovorum subsp. carotovorum on detached cabbage leaves resulted in an immune phenotype or a significant reduction in symptom development, depending on the peptide concentration. Cytotoxicity of the four hexapeptides was evaluated in mouse and human epithelial cell lines using an MTT test. The results revealed a lack of cytotoxic effects.
\end{abstract}

Keywords: AMP, synthetic, antimicrobial peptide, phytopathogenic bacteria, antibiotics, infection control, cytotoxicity, MTT test.

Bacterial diseases of plants are extremely problematic for the commercial agriculture industry because they are difficult to control and often precipitate disastrous economic consequences $[1,32]$. Current methods of controlling plant diseases rely primarily on the use of copper derivatives and antibiotics [31]. However, the utility of these compounds is limited owing to the emergence of antibiotic-resistant

*Corresponding author

Phone: +82-031-219-2620; Fax: +82-031-219-1615;

E-mail: emoon@ajou.ac.kr strains, regulatory constraints, and environmental and public health concerns. Recently, antimicrobial peptides (AMPs) have been intensively studied as an alternative to conventional antibiotics. Natural AMPs (usually less than 50 amino acid residues in length) have been isolated from virtually all groups of organisms, including bacteria, fungi, plants, and animals $[30,35]$. AMPs display tremendous sequence diversity and size variation but share common structural features, which include a net positive charge and amphipathic structure that facilitate their interaction with negatively charged biological membranes. Since cationic amino acid residues are abundant in AMPs, they are often called cationic antimicrobial peptides (CAMPs). In contrast to traditional antibiotics, AMPs possess certain advantages. For example, they show a broad spectrum of activity or target organism specificity depending on the AMP, low cytotoxicity against eukaryotic cells, and unique modes of action and cellular targets that are related to the low occurrence of resistant strains $[8,13,34]$.

Over the past decade, more than 900 natural AMPs have been isolated from various organisms (to view the database, visit http://www.bbcm.units.it/ tossi//) and their ability to kill various pathogens, including bacteria, fungi, viruses, and protozoa, have been reported [23, 30]. However, native defense peptides have some limitations for practical use owing to their low level of activity and poor bioavailability. Many synthetic analogues have been designed to overcome these limitations, resulting in improved antimicrobial activity. Some engineered synthetic peptides have been expressed in transgenic plants and have shown activity in vivo $[23,25,29]$. However, the isolation and characterization of new native peptide antibiotics, and the engineering and optimization of new synthetic analogs from native peptides require a tremendous expenditure of time, money, and effort for each candidate sequence. The combinatorial chemistry approach is considered to be another alternative capable of screening a diverse pool of individual peptides in a short period of time and identifying those that have new or improved properties $[3,7,20]$. 
Currently, there is a lack of control agents that are highly effective against economically important plant pathogens, such as the bacteria Xanthomonas spp., Pectobacterium spp., and Pseudomonas spp., which cause a serious loss of yield under both field and postharvest conditions $[1,9]$. This study was designed to discover new AMPs for the control of diseases caused by these phytopathogens. To this end, a synthetic combinatorial library was screened through a rapid positional scanning procedure that was described previously [6]. The four most effective antimicrobial hexapeptides were selected and their antimicrobial activity was evaluated using more than 20 phytopathogenic bacteria as well as some human pathogenic fungi. The cytotoxicity and actual potential to control plant disease in vivo were evaluated as well.

\section{Materials ANd Methods}

\section{Microbial Strains and Culture Conditions}

The strains used in this study are listed in Table 1. All fungal strains were grown in YPD medium ( $10 \mathrm{~g}$ yeast extract, $20 \mathrm{~g}$ peptone, and
$20 \mathrm{~g}$ dextrose in 11 of distilled water). Ralstonia and Burkholderia spp. were grown in either King's B $(\mathrm{KB})$ medium $(20 \mathrm{~g}$ proteose peptone No. 3, $1.5 \mathrm{~g} \mathrm{MgSO}_{4} \cdot 7 \mathrm{H}_{2} \mathrm{O}, 1.5 \mathrm{~g} \mathrm{KH}_{2} \mathrm{PO}_{4}$, and $15 \mathrm{ml}$ of glycerol in 11 of distilled water) or Luria-Bertani (LB) medium (10 g tryptone, $5 \mathrm{~g}$ yeast extract, and $10 \mathrm{~g} \mathrm{NaCl}$ in 11 of distilled water). Lactobacillus brevis was grown in deMan-Rogosa-Sharpe (MRS) medium (10 g proteose peptone No. 3, $10 \mathrm{~g}$ beef extract, $5 \mathrm{~g}$ yeast extract, $20 \mathrm{~g}$ dextrose, $1 \mathrm{~g}$ polysorbate $80,2 \mathrm{~g}$ ammonium citrate, $5 \mathrm{~g}$ sodium acetate, $1 \mathrm{~g} \mathrm{MgSO}_{4}, 0.05 \mathrm{~g} \mathrm{MnSO}_{4}$, and $2 \mathrm{~g} \mathrm{Na}_{2} \mathrm{HPO}_{4}$ in 11 of distilled water). All other strains were grown in LB. All of the strains were grown at $30^{\circ} \mathrm{C}$ except for $E$. coli $\mathrm{DH} 5 \alpha$, which was grown at $37^{\circ} \mathrm{C}$.

\section{Synthesis of Peptide Libraries and Individual Peptides}

A positional scanning synthetic peptide combinatorial library (PSSCL) package was purchased from the Peptide Library Support Facility (PLSF) of Pohang University of Science and Technology (POSTECH, Pohang, Korea). The peptide library was synthesized by solid-phase methods and simultaneous multiple peptide synthesis using $N$-(9-fluorenyl) methoxycarbonyl chemistry [12]. The hexapeptide SCL was synthesized in so-called PS format as previously described [16]. Mixture (X) positions were composed of a mixture of 19 amino acids (excluding cysteine) with relative ratios suitably adjusted to yield a close-to-equimolar ratio. Each amino acid was synthesized

Table 1. List of bacterial and fungal strains used in this study.

\begin{tabular}{|c|c|c|c|}
\hline Strain name & Habitat/host & Source & Abbreviation \\
\hline Acidovorax konjaci & Soil & KACC10652 & $\mathrm{AC}$ \\
\hline Bacillus subtilis & Soil & KACC 10113 & BS \\
\hline Burkholderia glumae R1 & Rice grain & [3] & BGR1 \\
\hline Burkholderia glumae SL 2387 & Rice grain & {$[1]$} & BG2387 \\
\hline Burkholderia glumae SL 2395 & Rice grain & {$[1]$} & BG2395 \\
\hline Burkholderia glumae SL 2399 & Rice grain & {$[1]$} & BG2399 \\
\hline Candida glabrata & Human & {$[2]$} & CGL \\
\hline Candida krusei & Human & {$[2]$} & CKR \\
\hline Candida tropicalis & Human & [2] & CTR \\
\hline Clavibacter michiganensis subsp. michiganensis & Pepper & KACC20122 & $\mathrm{CM}$ \\
\hline Corynebacterium glutamicum & Soil/grass & KACC 10784 & CG \\
\hline Escherichia coli $\mathrm{DH} 5 \alpha$ & Human & BRL com. & DH $5 \alpha$ \\
\hline Janibacter melonis & Melon/human & KACC20515 & $\mathrm{JM}$ \\
\hline Lactobacillus brevis & Spoiled beer & KACC 10553 & LAB \\
\hline Pantoea stewartii & Corn & {$[1]$} & PSP \\
\hline Pectobacterium carotovorum subsp. atrosepticum & Potato & [1] & PCA \\
\hline Pectobacterium carotovorum subsp. carotovorum & Potato & KACC 10226 & PCC \\
\hline Pseudomonas putida & Soil & {$[1]$} & $\mathrm{PP}$ \\
\hline Pseudomonas syringae pv. tomato DC 3000 & Tomato & {$[1]$} & DC3000 \\
\hline Ralstonia solanacearum race 1 & Potato & {$[1]$} & RS1 \\
\hline Ralstonia solanacearum race 3 & Potato & {$[1]$} & RS3 \\
\hline Saccharomyces cerevisiae 5312 & Human & {$[2]$} & S5321 \\
\hline Xanthomonas albilineans & Sugar cane & {$[1]$} & XAL \\
\hline Xanthomonas campestris pv. vesicatoria 833 & Pepper & [1] & XCV833 \\
\hline Xanthomonas campestris pv. vesicatoria 833 pilA & Pepper & pilA mutant of XCV833 & XCVM \\
\hline Xanthomonas oryzae pv. oryzae 599 & Rice & [1] & X599 \\
\hline Xanthomonas oryzae pv. oryzae 710 & Rice & {$[1]$} & X710 \\
\hline Xanthomonas oryzae pv. oryzae 090 & Rice & {$[1]$} & X090 \\
\hline
\end{tabular}

KACC: Korean Agricultural Culture Collection, Suwon, Korea; [1]: from Dr. S. G. Heu, National Institute of Agricultural Science and Technology, Suwon, Korea; [2]: from Dr. W. K. Kim, Department of Microbiology, Ajou University, Medical School, Suwon, Korea; [3]: from Dr. I. G. Hwang, Department of Applied Biology and Chemistry, Seoul National University, Seoul, Korea. Fungal strains are presented in bold type. 
with C-terminal amidation. One set of the library consisted of 114 tubes ( 6 positions $\times 19$ amino acids), and the concentration of the total peptides in a tube was $30 \mathrm{mM}$, whereas the concentration of an individual peptide was $12 \mathrm{nM}\left(30 \mathrm{mM} / 19^{5}\right)$.

Individual peptides were purchased from Peptron Co. (Daejeon, Korea). Each peptide was purified by preparative reverse-phase high-pressure liquid chromatography with a Shiseido Capcell Pak C18 column (Tokyo, Japan). Peptide identity was confirmed by mass spectrometric analysis on an HP 1100 series LC/MSD (HewlettPackard Co., Palo Alto, CA, U.S.A.). Each peptide, except watersoluble KRS22, was dissolved in 50\% dimethyl sulfoxide (DMSO) and stored at $-20^{\circ} \mathrm{C}$ after aliquoting. The final concentration of $10 \times$ stock solutions was $5 \mathrm{mM}$. The peptide grand average hydropathicity index (GRAVY) [18] was calculated using a Web-based tool (http:// www.expasy.org/tools/protparam.html).

\section{In Vitro Antimicrobial Activity Assay}

Peptide antimicrobial activity was measured in vitro using a microtiter plate assay as previously described [21]. Ninety $\mu \mathrm{l}$ of freshly diluted overnight culture (with a final concentration of $5 \times 10^{5}$ cells after 16 to $24 \mathrm{~h}$ incubation) was mixed with $10 \mu \mathrm{l}$ of peptide mixture from the PS-SCL. Growth rate was measured during 16 or $48 \mathrm{~h}$ incubation, depending on the strain, at $595 \mathrm{~nm}$ (A595) in a Bio-Rad microplate reader 550 (Japan). For all treatments, at least three replicates were prepared. The mean blank A595 value from one row of mock inoculations was subtracted from the A595 value for each well, and the mean and standard deviation (SD) were then calculated for each treatment.

The assay for inhibition of growth by sequence-defined peptides was essentially the same. Two concentrations of peptides were applied: $10 \mu \mathrm{M}$ and $100 \mu \mathrm{M}$. One hundred eighty $\mu \mathrm{l}$ of freshly diluted overnight culture (adjusted to $5 \times 10^{5}$ cells) was mixed with $20 \mu$ of $10 \times$ peptide stock solution and incubated for 16 to $48 \mathrm{~h}$ with gentle shaking ( $80 \mathrm{rpm})$. The OD was measured at $595 \mathrm{~nm}$ and the relative survival value was determined. For the fungal strains, the same basic treatment was applied except that the initial concentration was adjusted to $1 \times 10^{5}$ cells.

\section{Minimal Effective Concentration}

To visualize the activity of the selected hexapeptides, a growth inhibition assay was performed on solid medium. The lowest concentration that created a clear zone was defined as the minimal effective concentration (MEC) [11, 14,37]. A $1 \mathrm{mM}$ peptide stock solution was serially diluted $1: 1$ seven times in sterile water. A $5 \mu 1$ aliquot of each sample was then spotted onto a plate and allowed to dry for $15 \mathrm{~min}$. The first spot of each series contained 5 nmole of peptide. The plate was overlaid with $7 \mathrm{ml}$ of soft top agar $(0.7 \% \mathrm{w} / \mathrm{v})$ mixed with $100 \mu 1\left(10^{6}\right.$ cells $)$ of the indicator strain. Each treatment was performed in triplicate. Plates were photographed after $24 \mathrm{~h}$ incubation at $30^{\circ} \mathrm{C}$. The results were expressed as the total amount of hexapeptide (nmoles) that was spotted onto the solid medium. When formation of a turbid zone followed formation of a clear zone of inhibition, the MEC was taken to be the average of the final two dilutions.

\section{Leaf Inoculation Test}

Five leaves of fresh Chinese cabbage (Brassica rapa var. pekinensis subtype won bok) were detached and surface sterilized by spraying with diluted commercial bleach solution $(5 \%, v / v)$. Leaf surfaces were spray-washed with sterilized water and gently blotted with a paper towel. After air drying for $15 \mathrm{~min}$, the leaves were wounded by puncturing at three sites using a pencil cap $(0.7 \mathrm{~cm}$ in diameter). A $10 \mu \mathrm{l}$ suspension $\left(1 \times 10^{7} \mathrm{CFU} / \mathrm{ml}\right)$ of an overnight culture of the soft rot pathogen Pectobacterium carotovorum subsp. carotovorum (PCC) was applied to the wounded leaf surface. For the peptide treatment, $10 \mu \mathrm{l}$ of 50,100 , or $200 \mu \mathrm{M} \mathrm{KCM} 21$ solution was applied $1 \mathrm{~h}$ before or $1 \mathrm{~h}$ after inoculation or concomitantly with the bacterial suspension. For each treatment, five replicates were inoculated. Treated leaves were maintained at $28^{\circ} \mathrm{C}$ and $85 \%$ relative humidity. Symptom development was scored for 2 days by measuring the diameter of the rotted tissue. A mock inoculation or peptide inoculation without bacteria did not produce any symptoms under these conditions (data not shown).

\section{In Vitro Cytotoxicity Test}

Three human cell lines and one mouse cell line were used for the in vitro toxicity test: human endometrial cancer cell line Hec1A (American Type Culture Collection [ATCC], Manassas, VA, U.S.A.), a primary culture of a human endometrial stroma cell line (Dr. Min, Department of Biological Science, Ajou University, Suwon, Korea), normal human gingival fibroblast cell line HGF (ATCC), and mouse embryonic cell line NIH-3T3 (Korean Cell Line Bank [KCLB], Seoul, Korea). Cells were cultured in RPMI 1640 medium (GibcoBRL) containing $5 \%$ fetal bovine serum at $37^{\circ} \mathrm{C}$ for $24 \mathrm{~h}$ in a $\mathrm{CO}_{2}$ incubator prior to exposure to $100 \mu \mathrm{M}$ peptide dissolved in $1 \% \mathrm{DMSO}$ solution. Treated cells were examined for viability as determined by their ability to reduce 3-(4,5-dimethylthiazol-2-yl)-2,5 diphenyltetrazolium bromide (MTT). Detection of the cellular conversion of MTT to water-insoluble colored formazan was performed according to the procedure described previously [26]. Briefly, after $24 \mathrm{~h}$ treatment, $50 \mu \mathrm{l}$ of MTT (Sigma) was added to the solution and incubated for $3 \mathrm{~h}$. One hundred fifty $\mu \mathrm{l}$ of DMSO was then added, followed by shaking for $10 \mathrm{~min}$ to release the formazan.

\section{Results}

\section{Selection of Antimicrobial Hexapeptides Through Screening of a PS-SCL}

For the PS-SCL assay, the growth rate was measured to evaluate the effective inhibition of each amino acid residue at a defined position $[4,19]$. The phytopathogenic bacterium Xanthomonas campestris pv. vesicatoria strain 833 (XCV833) was used as a test strain. A number of mixtures were strongly inhibitory, and there were clear differences between inhibitory and non-inhibitory mixtures (Fig. 1). The PS-SCL assay was also performed with the Gram-positive phytopathogenic bacterium Clavibacter michiganensis subsp. michiganensis (CM) and the broad-spectrum phytopathogenic bacterium Ralstonia solanacearum race 3 (RS3). Although there were some variations, the assay with CM identified similar amino acid residues at the same positions as did the assay with XCV833 (see below for details), whereas no obvious inhibitory effects on RS3 were detected (Table 2).

In the initial assay with strain XCV833, the mixtures that showed significant inhibition of growth were found in 


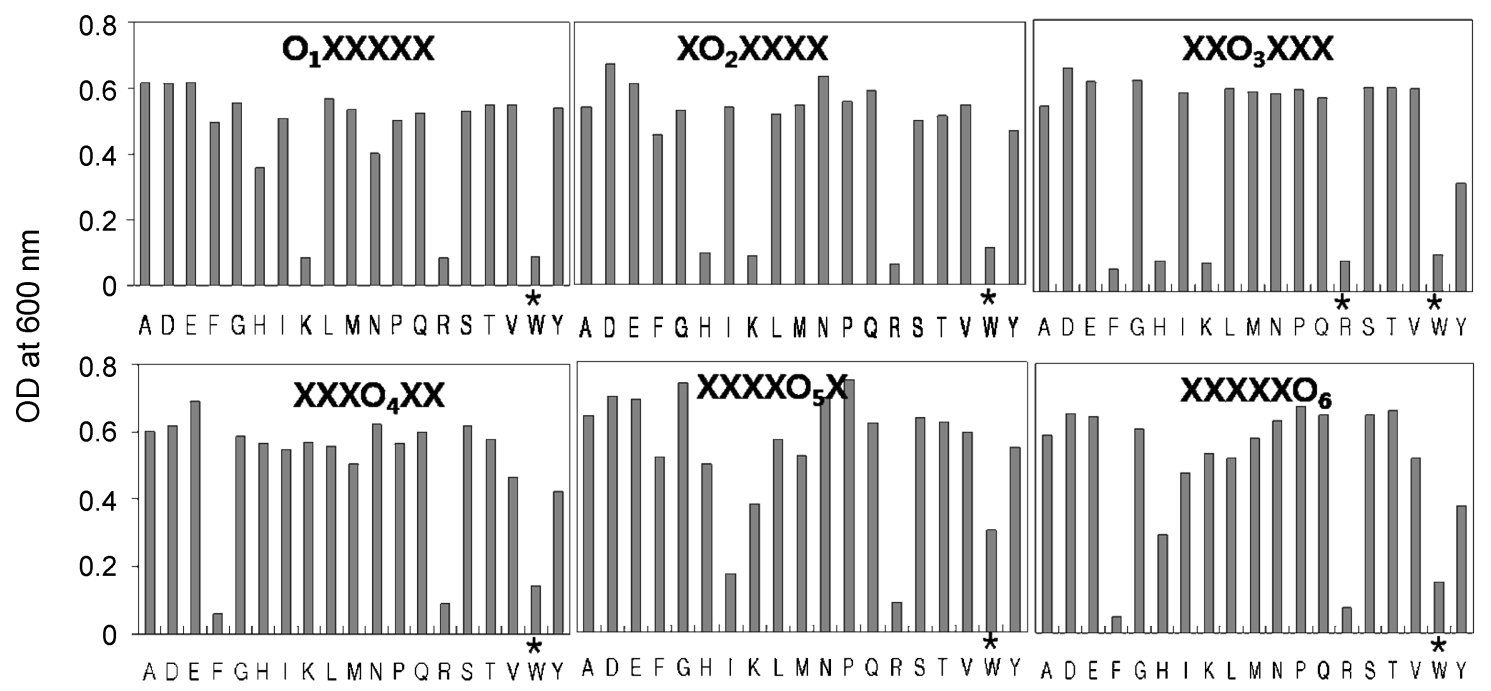

Fig. 1. Positional scanning of synthetic peptide combinatorial library (PS-SCL).

PS-SCL was conducted against Xanthomonas campestris pv. vesicatoria strain 833 (XCV833). Each panel represents the result obtained with peptide pools with known amino acids at each of the six positions of the hexapeptides. The six positions are individually defined $\left(\mathrm{O}_{1}\right.$ and $\left.\mathrm{O}_{2} \ldots\right)$ with each of the $19 \mathrm{~L}-$ amino acids. The remaining five positions consist of the mixtures (X) of $19 \mathrm{~L}$-amino acids (excluding cysteine). The library consists of 114 peptide pools; the PS-SCL in total is made up of 47,045,881 different peptides. Each peptide mixture was assayed against an overnight culture of XCV833 (diluted to 1$\left.5 \times 10^{6}\right)$ in 96 -well microtiter plates. Bacterial cells were incubated for $24 \mathrm{~h}$ at $30^{\circ} \mathrm{C}$ with shaking $(80 \mathrm{rpm})$. Bacterial growth rate was measured with a microplate reader. The asterisks indicate peptide pools inducing instant agglutination as evidenced by turbidity in the well immediately after treatment. Each letter on the $\mathrm{X}$-axis is a 1-letter symbol for an amino acid.

all six positions, indicating that all of these positions are important. In this assay, lysine, arginine, and tryptophan residues were selected at positions 1 and 2 , and a histidine residue was additionally selected at position 2; phenylalanine, histidine, lysine, arginine, and tryptophan were selected at position 3; phenylalanine, arginine, and tryptophan were selected at position 4; isoleucine, arginine, and tryptophan were selected at position 5; and phenylalanine, histidine, arginine, and tryptophan were selected at position 6 . Results of the assay with CM showed a less obvious difference between inhibitory and non-inhibitory tubes, especially at positions 1 and 2. Based on this assay, the selected residues were lysine and tryptophan at position 1 , tryptophan at position 2 , arginine and tryptophan at position 3, and arginine and tryptophan at positions 4,5 , and 6. Most of the residues identified from this assay share common features with the amino acid residue profile of the initial assay. Although only a few library mixtures showed activity at each position, integration of the results generated a large number of potential combinations for further testing. The selected amino acid residues are either positively charged (arginine or lysine) or contain aromatic rings (tryptophan or phenylalanine) or both (histidine). The predominant appearance of these types of residues corresponds to results from previous studies $[4,13,19]$.

In our deconvolution process, the first set of individual hexapeptides was designed based on the results of the initial screening with XCV833. This set contained 9 different hexapeptides of which 6 are simple peptides and 3 are compound peptides containing more than a single amino acid at each position: WWWWWW-NH $\mathrm{H}_{2}$ [KI-1], KRFWRF$\mathrm{NH}_{2}$ [K833-1], NRYFRH-NH ${ }_{2}$ [KKCC-1], LRWFIH-NH [KRS-1], YDEGGE-NH ${ }_{2}$ [K-N], RRWWRF-NH ${ }_{2}$ [K-P], WW(R,W)W(W,I)W-NH ${ }_{2}$ [KIC-2], K(R,K)(F,K)(W,F)R(F,H)-

Table 2. Amino acid residues identified by PS-SCL.

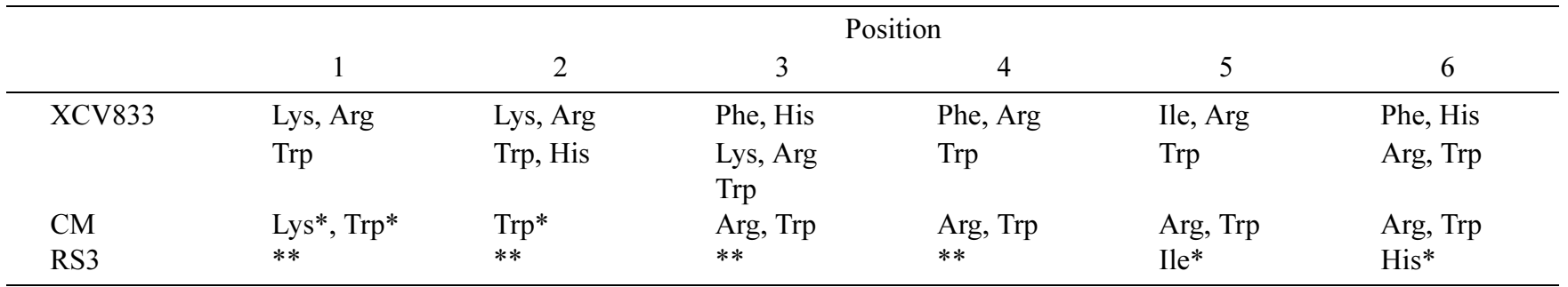

*: Minor growth inhibition was observed.

**: No obvious amino acid residues were identified. 
Table 3. Twelve hexapeptides selected based on PS-SCL.

\begin{tabular}{lll}
\hline No. & Name & Sequence* \\
\hline 1 & ECM1 & EDDDDD \\
2 & ECM2 & WEDDDG \\
3 & $\underline{\text { KCM11 }}$ & $\underline{\text { TWWRWW }}$ \\
4 & $\underline{\text { KCM12 }}$ & $\underline{\text { KWRWIW }}$ \\
5 & $\underline{\text { KCM21 }}$ & $\underline{\text { KWWWRW }}$ \\
6 & KCM22 & NFFFWR \\
7 & KCM23 & NRFFWH \\
8 & KPC22 & WRWFIH \\
9 & $\underline{\text { KRS22 }}$ & KRFFRF \\
10 & KC21 & WKFFRH \\
11 & KC22 & KXXXRX \\
12 & KIIC-1 & \\
\hline
\end{tabular}

Four highly effective peptides (underlined) were selected for further study.*Each peptide was synthesized with C-terminal amidation. X: Random amino acids (excluding cysteine).

$\mathrm{NH}_{2}$ [KIIC-1], and (N,L)R(Y,F)F(R,I)(F,H)-NH $\mathrm{N}_{2}$ [KIIC-2]. Peptide activity levels were evaluated by measuring the relative survival rates of bacterial strains XCV833, CM, RS3, and PCC (data not shown). Among the first nine individual hexapeptides, the compound peptide KIIC-1 had the highest activity, whereas KRS-1 had the highest activity among the six simple peptides. However, KIIC-1 exhibited low-to-moderate cytotoxicity when evaluated by the MTT test (data not shown).

The second set of 11 simple peptides was designed based on the integration of the results from the three library screenings as well as the composition of KIIC-1 (Table 3). ECM1 and ECM2 were designed with residues that either did not inhibit growth or slightly enhanced growth (Fig. 2), and they were used as secondary negative controls in addition to a mock control in subsequent experiments.

\section{Comparison of Hexapeptide Activity}

Relative bacterial survival rates in the presence of each of the second set of hexapeptides were evaluated (Fig. 2). The relative survival rate of the Gram-negative bacterium XCV833 was less than 0.3 in the presence of KCM11, KCM12, KCM21, KCM22, KCM23, KRS22, and KIIC-1 at the high concentration $(100 \mu \mathrm{M})$. At the low concentration $(10 \mu \mathrm{M})$, the relative survival rate of XCV833 was less than 0.3 in the presence of only two hexapeptides, KCM12 and KIIC-1. The relative survival rate of the Gram-positive bacterium CM was less than 0.3 in the presence of KCM11, KCM12, KCM21, $\mathrm{KCM} 23$, KRS22, and KIIC-1 at the high concentration and was less than 0.3 in the presence of only three hexapeptides, KCM11, KCM21, and KIIC-1, at the low concentration. Among the simple hexapeptides, KCM11 showed the highest activity against XCV833 and CM at the high concentration. However, the activity of KCM11 against XCV833 was diminished at the low concentration. The activity of KCM12 against XCV833 was lower than that
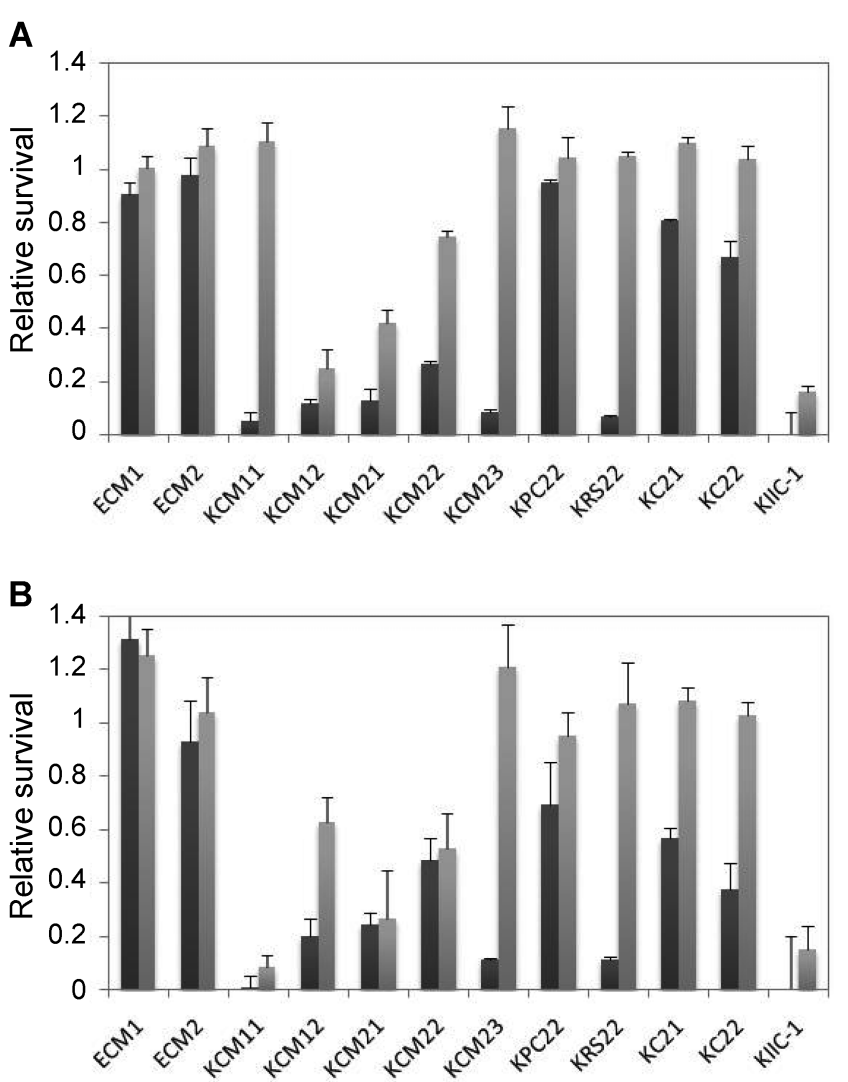

Fig. 2. Comparison of survival rates in the presence of the 12 synthetic hexapeptides.

In order to choose peptides for further study, rates of growth inhibition (represented by relative survival) were evaluated by incubating two bacterial strains in the presence of $100 \mu \mathrm{M}$ (black bar) or $10 \mu \mathrm{M}$ (grey bar) of synthetic hexapeptide, respectively. A. Xanthomonas campestris pv. vesicatoria 833 (Gram-negative); B. Clavibacter michiganensis subsp. michiganensis (Gram-positive).

of KCM11 at the high concentration, whereas its activity was higher than that of KCM11 at the low concentration. The activity of KCM21 against XCV833 and CM was similar to that of KCM11. KRS22 showed high activity against XCV833 and CM at the high concentration, but its activity was drastically reduced at the low concentration. Based on these results, four hexapeptides, KCM11, KCM12, KCM21, and KRS22, were selected for further study.

\section{Activity Profiles of the Selected Hexapeptides}

The growth inhibition assay was extended to examine the activity profiles of the selected hexapeptides against various bacteria, including Gram-negative strains Ralstonia solanacearum (RS1 and RS3) and E. coli (DH5 $\alpha$ ), and Gram-positive strains Bacillus subtilis (BS), Corynebacterium glutamicum (CG), and Lactobacillus brevis (LAB) (Fig. 3). The four hexapeptides exhibited differences in specificity. In general, they were more active against Gram-positive strains; the relative survival rate of Gram-negative strains was up to $100 \%$, whereas that of Gram-positive strains was up to 

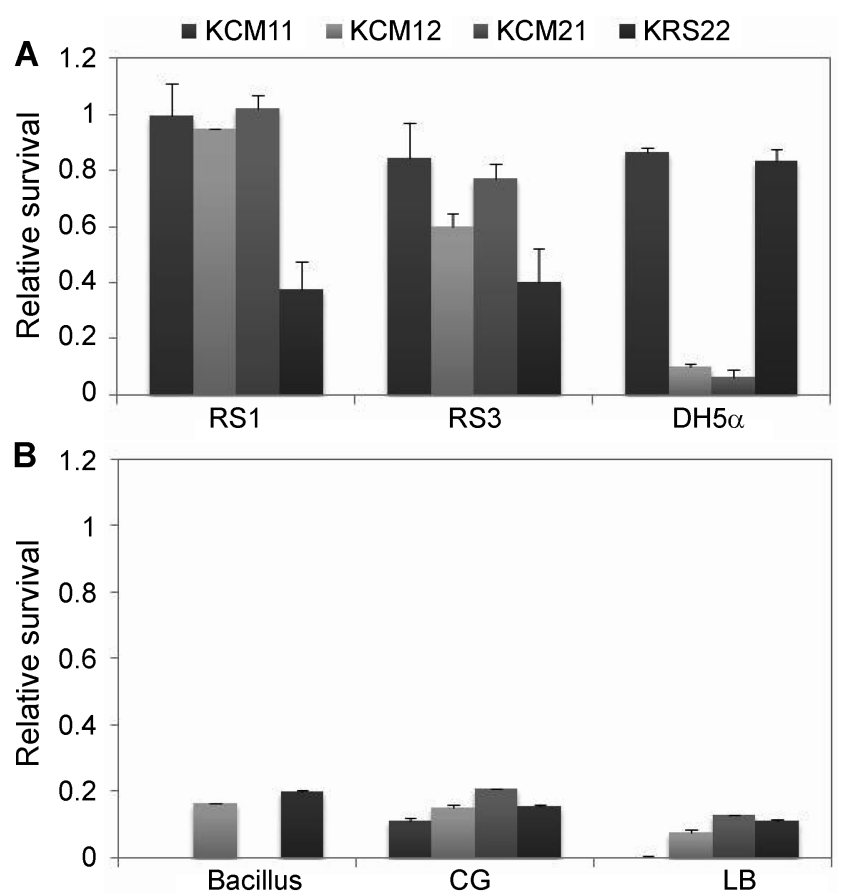

Fig. 3. Selective inhibition of growth of Gram-positive and Gram-negative bacteria by four hexapeptides.

Inhibition of growth was compared between or within Gram-positive (A) and Gram-negative (B) species in the presence of $100 \mu \mathrm{M}$ of each hexapeptide. Growth was measured by a spectrophotometer at $600 \mathrm{~nm}$ after $17 \mathrm{~h}$ incubation. Relative survival values were calculated based on the value obtained for the non-treated control. A. RS1: Ralstonia solanacerum race 1 (RS1); RS3: Ralstonia solanacerum race 3; and DH5 $\alpha$ : Escherichia coli DH5a. B. BS: Bacillus subtilis; CG: Corynebacterium glutamicum; and LAB: Lactobacillus brevis.

$20 \%$ (Fig. 3). The inhibitory activity of the four hexapeptides varied depending on the species as well. Whereas KCM12 and KCM21 showed high activity against E. coli DH5 $\alpha$, the activity of these peptides against Ralstonia spp. was low. KRS22 showed significant activity against the two

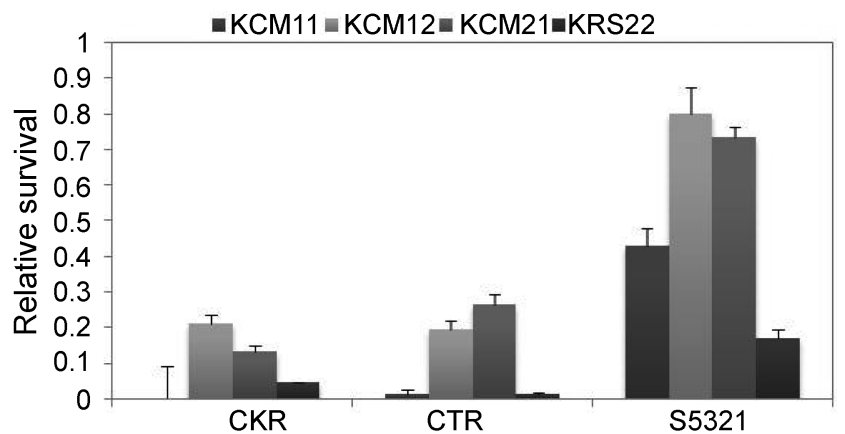

Fig. 4. Effect of four hexapeptides on fungal growth.

Relative rate of survival was compared among non-filamentous human pathogenic fungi in the presence of $100 \mu \mathrm{M}$ of each hexapeptide. Growth was measured by a spectrophotometer at $600 \mathrm{~nm}$ after $21 \mathrm{~h}$ incubation. Relative survival values were calculated based on the value obtained for the non-treated control. CKR: Candida krusei; CTR: Candida tropicalis; S5321: Saccharomyces cerevisiae 5312.
Table 4. Clear zone (MEC) assay against 21 bacterial strains (nmole).

\begin{tabular}{llcccc} 
Strains & Media & KCM11 & KCM12 & KCM21 & KRS22 \\
\hline AC & LB & 2.5 & 1.3 & 0.6 & 5 \\
BG2387 & KB & $\mathrm{x}$ & $\mathrm{x}$ & $\mathrm{x}$ & $\mathrm{x}$ \\
BGR2395 & KB & $\mathrm{x}$ & $\mathrm{x}$ & $\mathrm{x}$ & $\mathrm{x}$ \\
BGR2399 & KB & $\mathrm{x}$ & $\mathrm{x}$ & $\mathrm{x}$ & $\mathrm{x}$ \\
BGR1 & KB & $\mathrm{x}$ & $\mathrm{x}$ & $\mathrm{x}$ & $\mathrm{x}$ \\
CM & LB & 0.3 & 0.6 & 0.3 & 2.5 \\
DC3000 & LB & 5 & 0.3 & 0.6 & 2.5 \\
DH5a & LB & $\mathrm{x}$ & 1.3 & 1.3 & 5 \\
PCA & LB & 5 & 0.6 & 0.6 & 2.5 \\
PCC & LB & $\mathrm{x}$ & 5 & 5 & $\mathrm{x}$ \\
PP & LB & $\mathrm{x}$ & 0.6 & 1.3 & $\mathrm{x}$ \\
RS1 & KB & $\mathrm{x}$ & $\mathrm{x}$ & $\mathrm{x}$ & $\mathrm{x}$ \\
XAL & LB & 0.3 & 1.3 & 0.2 & 2.5 \\
XCV833 & LB & 0.3 & 0.3 & 0.2 & 2.5 \\
XCVM & LB & 0.3 & 0.3 & 0.2 & 2.5 \\
XOO 90 & PSA & 1.3 & 0.2 & 0.3 & 1.3 \\
XOO 599 & PSA & 1.3 & 0.2 & 0.2 & 0.6 \\
XOO 710 & PSA & 1.3 & 0.2 & 0.3 & 1.3 \\
\hline
\end{tabular}

$\mathrm{x}$ : No clear zone at the highest concentration.

Ralstonia strains even though its overall activity against the other bacteria was relatively low compared with the other three hexapeptides. KCM11 showed relatively low activity against the Gram-negative strains but its activity against the Gram-positive strains was high.

The growth inhibition assay was also extended to include the non-filamentous human fungal pathogens Candida krusei (CKR), Candida tropicalis (CTR), and Saccharomyces cerevisiae (S5321) (Fig. 4). Among the four hexapeptides, KCM11 was the most effective against Candida spp., whereas KRS22 had a significant effect on the growth of S5321. KCM12 and KCM21, which had a large effect on $E$. coli $\mathrm{DH} 5 \alpha$, showed low activity against all of the fungal pathogens tested. This result indicates that the hexapeptides may be more specific for either fungal or bacterial pathogens.

\section{Clear Zone (MEC) Assay of Bactericidal Activity}

In order to determine whether the selected hexapeptides are actually bactericidal, we subjected them to the clear zone assay to measure the MEC against 20 phytopathogenic strains (Table 4). Whereas KCM21 showed the highest activity against most of the strains tested, KRS22 showed the lowest activity. The activity of KCM12 and KCM11 varied depending on the species. Among those tested, the species that was the most sensitive to KCM12 was Xanthomonas oryzae pv. oryzae (XOO) (Table 4). All three strains of XOO showed similar sensitivity to KCM11, KCM12, and KCM21. However, XOO599 was more sensitive to KRS22 than were the other two strains (Table 4). It is 
Table 5. Effect of growth medium on MEC (nmole).

\begin{tabular}{llcccc}
\hline Strains & Media & KCM11 & KCM12 & KCM21 & KRS22 \\
\hline DC3000 & LB & 5 & 0.3 & 0.6 & 2.5 \\
& KB & x & 1.3 & 2.5 & 1.3 \\
PP & LB & x & 0.6 & 1.3 & x \\
& KB & x & x & x & x \\
RS1 & LB & ng & ng & ng & ng \\
& KB & x & x & x & x \\
XAL & LB & 0.3 & 1.3 & 0.2 & 2.5 \\
& KB & 1.3 & 2.5 & 0.6 & 5 \\
\hline
\end{tabular}

ng: No growth; $x$ : no clear zone at the highest concentration.

noteworthy that all of the bacterial strains grown in LB were sensitive to at least three hexapeptides; however, PCC and PP were insensitive to KCM11 as well as KRS22.

$\mathrm{KB}$ is a differential medium that supports the growth of pseudomonads and related species, such as Ralstonia spp., Acidovorax spp., and Burkholderia spp. Some pseudomonads can be grown in LB medium as well (Table 5). In order to determine whether bactericidal activity is affected by the growth medium, Pseudomonas syringae pv. tomato DC3000, which can be grown in both $\mathrm{KB}$ and $\mathrm{LB}$, was subjected to the clear zone assay on each medium. As shown in Fig. 5, there was a significant difference in the size of the clear zone depending on the medium. This result was confirmed using other bacterial strains (Table 5).

\section{Evaluation of Cytotoxic Effects by the MTT Test}

The cytotoxic activity of the four hexapeptides was determined using normal endometrial stroma cells and Hec1A human endometrial cancer cells (Fig. 6). Since the hexapeptides $(100 \mu \mathrm{M})$ were dissolved in $1 \%$ DMSO, their cytotoxicity was compared with a $1 \%$ DMSO control. DMSO alone showed some cytotoxicity. The relative survival rates of

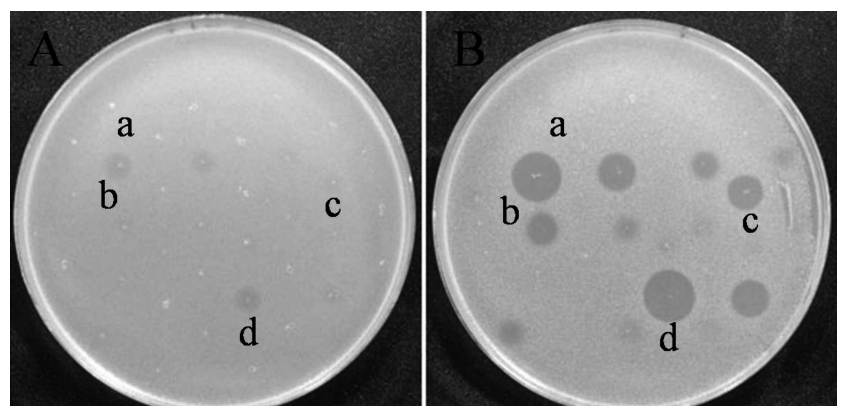

Fig. 5. Comparison of activity profiles in two different media. The bacterial strain Pseudomonas syringae pv. tomato DC3000 was subjected to the clear zone assay in two different media. The first spot of each series contains 5 nmole of peptide in $5 \mu 1$ solution. A 1:1 dilution series was spotted immediately after the first spot and was dried for $15 \mathrm{~min}$. Seven $\mathrm{ml}$ of soft top agar $(0.7 \%, \mathrm{w} / \mathrm{v})$ was mixed with $100 \mu \mathrm{l}$ $\left(10^{5}\right.$ cells) of the indicator strain and overlaid onto the plate. The plate was photographed after $24 \mathrm{~h}$ incubation at $30^{\circ} \mathrm{C}$. Left Panel: $\mathrm{KB}$ medium. Right Panel: LB medium. Lowercase letters indicate the first spot of each dilution series of (a) KCM11, (b) KCM12, (c) KCM21, and (d) KRS22, respectively.

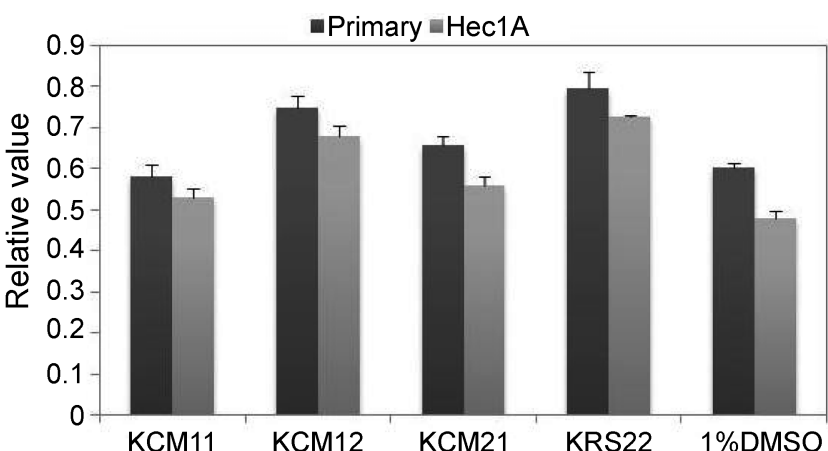

Fig. 6. Cytotoxic effects on mammalian cells.

A primary culture cell line (human endometrial stroma cells) and a human endometrial cancer cell line (Hec1A) were subjected to the MTT test. Treatment with $1 \%$ DMSO was used as a control.

the normal cell line and the cancer cell line were 0.6 and 0.5 , respectively. None of the four hexapeptides showed any cytotoxicity when compared with the DMSO control. Interestingly, the normal cell line was less sensitive to the hexapeptides than the cancer cell line. The noncytotoxic effect of the selected hexapeptides was confirmed with the normal human gingival fibroblast cell line HGF-1 as well as the mouse embryonic cell line NIH-3T3 (data not shown).

\section{In Vivo Activity of KCM21}

In order to determine whether the hexapeptides actually stop the infection process in vivo, we chose a bacterial soft rot model system in which Chinese cabbage was the host and PCC was the pathogen. KCM21 at three different concentrations $(50,100$, and $200 \mu \mathrm{M})$ was applied one hour before (B), one hour after (A), or concomitantly with (C) inoculation (Fig. 7). When KCM21 was applied before inoculation, no effect on symptom development was detected at any of the peptide concentrations. However, both the post-inoculation and concomitant treatments had a significant effect on symptom development. The strongest inhibition

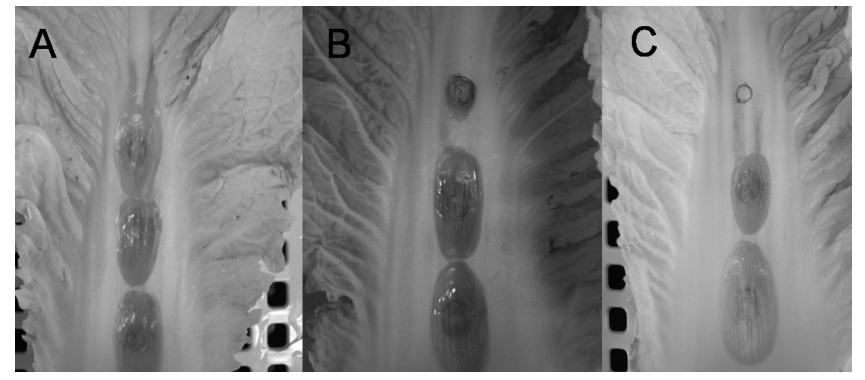

Fig. 7. Effect of KCM21 on development of symptoms caused by PCC.

In each Chinese cabbage leaf, top, middle, and bottom spots were injected with 200,100 , and $50 \mu \mathrm{M}$ of KCM21, respectively, either concomitantly with $(\mathbf{C})$, one hour before $(\mathbf{B})$, or one hour after $(\mathbf{A})$ pathogen inoculation. Inoculated leaves were maintained at $28^{\circ} \mathrm{C}$ and $85 \%$ relative humidity, and then photographed 2 days later. 


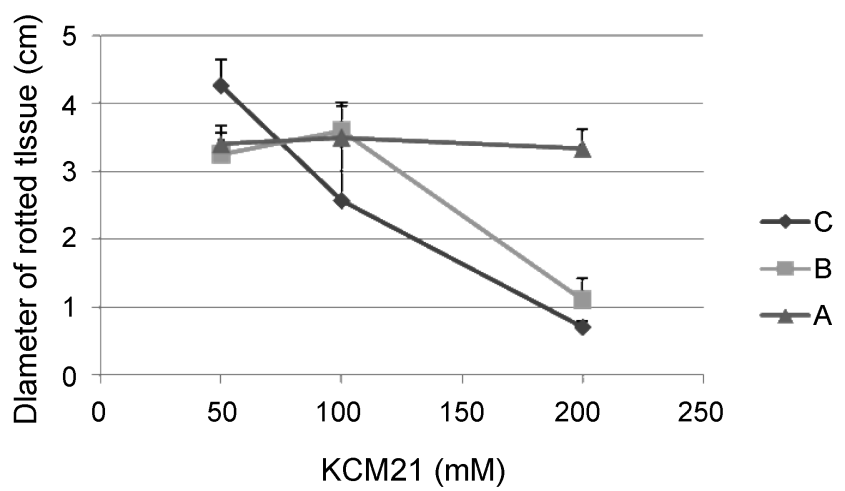

Fig. 8. Dose-dependent effect of KCM21 on development of symptoms caused by PCC.

Three different concentrations of KCM21 were applied to leaves concomitantly with $(\mathbf{C})$, one hour before (B), or one hour after (A) pathogen inoculation. The diameter of rotted tissue was measured 2 days after inoculation.

of tissue damage was achieved when the peptide was applied concomitantly with the inoculum. Whereas symptom development was not affected by treatment with $50 \mu \mathrm{M}$ KCM21, treatment with $100 \mu \mathrm{M}$ peptide resulted in about a $40 \%$ reduction in the diameter of rotted tissue, and treatment with $200 \mu \mathrm{M}$ peptide completely stopped symptom development (Fig. 8).

\section{DisCUSSION}

The four AMPs selected in this study contain several hydrophobic/aromatic amino acid residues and one or two positively charged residues, and their composition profiles are in agreement with those of many previously reported AMPs [13]. All four peptides have a net positive charge and negative GRAVY (Table 6). KCM12 and KCM21 have two positively charged amino acid residues, whereas KCM11 and KRS22 have only one. In terms of GRAVY, KCM21 has the highest hydrophobicity $(-2.0)$ and KRS22 has the lowest (-0.367). The molecular mass of the peptides is around $1 \mathrm{kDa}$ and ranges from $943.09 \mathrm{kDa}$ for KRS22 to 1,046.21 $\mathrm{kDa}$ for KCM21.

In the growth inhibition experiment, the four selected hexapeptides showed activity against a variety of organisms, including Gram-positive and Gram-negative bacteria, Candida, and yeast, although the activity against yeast was relatively

Table 6. Physical properties of selected hexapeptides.

\begin{tabular}{|c|c|c|c|c|}
\hline Peptide & Sequence & Net charge $^{a}$ & IP & M.W. GRAVYb \\
\hline KCM11 & TWWRWW & 0.91 & 10.04 & $1,019.14-1.467$ \\
\hline KCM12 & KWRWIW & 1.91 & 11.05 & $973.16-1.100$ \\
\hline KCM21 & KWWWRW & 1.91 & 11.05 & $1,046.21-2.000$ \\
\hline KRS22 & WRWFIH & 1.08 & 10.05 & $943.09-0.367$ \\
\hline
\end{tabular}

\footnotetext{
${ }^{\mathrm{a}}$ Estimated at $\mathrm{pH}$ 7. ${ }^{\mathrm{b}}$ Peptide GRAVY index.
}

low (Figs. 3 and 4). However, it should be noted that there is a certain degree of specificity for target organisms. So far, the determinant for target organism specificity has not been well elucidated; however, there are reports that suggest a sequence-activity relationship. Lopez-Garcia et al. [19] demonstrated that a single residue substitution abolished the activity of the antifungal hexapeptide PAF20 and closely related peptides. They also showed that very closely related fungi within a genus or species were insensitive to PAF20 and suggested that some unknown component may be responsible for the specificity of both the peptide and the fungi tested. Altering antimicrobial properties by making minor changes in amino acid sequence have been reported elsewhere $[5,15]$. In this study, a variation in peptide activity within species was evident. For example, the sensitivity to KCM12 differed significantly between XAL and XCV833 (Table 4). In addition, among the XOO strains, XOO599 was more sensitive to KCM21 and KRS22, indicating that differences in specificity can exist even at the subspecies level.

The clear zone assay was performed with a variety of phytopathogenic strains to determine whether the peptides actually kill bacterial cells. All the strains tested were Gram-negative except for Clavibacter michiganensis subsp. michiganensis (CM). Interestingly, KCM11 showed relatively low activity against most of the bacterial strains; however, it showed high bactericidal activity against CM. This result indicates that KCM11 may have specificity for CM or Gram-positive bacteria in general. It is noteworthy that KCM11 is the only hexapeptide selected that contains a threonine residue in the first position; the other residues are common among the selected peptides. Munoz et al. [27] reported that adding an amino acid residue to the first position of hexapeptide PAF26 changed its specificity, and its activity strongly depended on the type of amino acid added.

KCM12 and KCM21 are very similar in terms of amino acid composition as well as target organism specificity. Both peptides showed high activity against most of the Gram-negative bacterial strains tested (Table 4) and both have a net charge of +2 . However, KCM21 has higher hydrophobicity as well as higher activity. On the other hand, KRS22 showed relatively low activity against most of the bacterial strains tested in the clear zone assay, and it has the lowest hydrophobicity and net charge $(+1)$ among the four peptides. These data suggest that higher hydrophobicity could be another factor affecting activity, although sequence specificity may be a prerequisite for bactericidal activity. The correlation between hydrophobicity or net charge and bactericidal activity has been reported in many studies. Chen et al. [10] modified the hydrophobicity of an AMP by systematically replacing leucine residues with less hydrophobic alanine residues or vice versa, and showed that higher hydrophobicity was correlated with higher killing 
activity. They also suggested that high antimicrobial activity could be obtained by choosing peptides from within an "optimum hydrophobicity window"; selecting peptides with hydrophobicity levels outside this window could result in a dramatic decrease in antimicrobial activity [10, 22, 27].

In the growth inhibition assay, KRS22 showed substantial activity against RS1 and RS3 in KB. However, in the clear zone assay, this hexapeptide showed no bactericidal activity, even at the highest concentration (Table 4). This result indicates that KRS22 may have bacteriostatic activity and weak bactericidal activity. In general, there is not always a precise distinction between bacteriostatics and bactericides; high concentrations of most bacteriostatic agents are also bactericidal, whereas low concentrations of bactericidal agents are only bacteriostatic (e.g., tetracyclines, sulfonamides, spectinomycin, etc.).

In the clear zone assay, a group of species were identified that showed insensitivity to all four hexapeptides (Table 4). Since these strains, which include Ralstonia spp. and Burkholderia spp., are related to Pseudomonas spp., all of them were grown on $\mathrm{KB}$ plates. $\mathrm{KB}$ is a differential medium that is used to distinguish between fluorescence-producing subtypes of pseudomonads. It contains $6 \mathrm{mM} \mathrm{MgSO}_{4}$ as a mineral and glycerol as a carbon source. Aside from the nutritional value of these components, glycerol is known to be a membrane stabilizer; therefore, its presence in the medium may reduce the activity of AMPs due to stabilization of lipid bilayers. In addition, it has been reported that increasing the ionic strength of the medium weakens electrostatic charge interactions that are necessary for initiating peptide-target interactions, thereby potentially reducing antimicrobial activity [36]. AMP antimicrobial activity is also counteracted to varying degrees by physiological concentrations of divalent cations (e.g., 1-2 $\mathrm{mM} \mathrm{Mg}^{2+}$ and $\mathrm{Ca}^{2+}$ ), monovalent cations (e.g., $100 \mathrm{mM} \mathrm{Na}^{+}$and $\mathrm{K}^{+}$), and polyanions [13]. Besides the electrostatic charge interaction, there is another mechanism to explain the antagonistic role of divalent cations in this context. In many species of Gram-negative bacteria, the charge on the outer membrane is controlled by the PhoPQ regulon. Bader et al. [2] suggested a model in which the PhoQ sensor is activated during the binding of AMPs by the displacement of divalent cations from PhoQ metal binding sites. Upon activation of the membrane-bound PhoQ sensor, which has a highly acidic surface, the membrane becomes more positively charged, resulting in increased tolerance to AMPs. All of these findings support the notion that highly stringent media or high concentrations of divalent cations may inhibit the action of KRS22 in KB.

When the hexapeptides were evaluated by the MTT test, there was no indication of cytotoxicity (Fig. 6). The basis for the differences in target membrane specificity between microbes and multicellular organisms has been well established. In the case of microbes, anionic lipids are present on the outer surface of the membrane, whereas in mammalian cells they are present along the cytoplasmic side of the membrane. This feature may account for the preferential activity of AMPs against bacteria versus mammalian cells. Cholesterol, which stabilizes lipid bilayers and may interact with peptides in target membrane, is known to reduce the activity of AMPs in mammals [24].

The bacterium Pectobacterium carotovorum subsp. carotovorum (PCC) is one of the main pathogens that cause soft rot in a variety of economically important crop plants belonging to Cruciferae as well as Solanaceae. PCC is one of the most problematic pathogens in the agricultural industry worldwide owing to its broad host range and ability to infect intact plants as well as vegetative tissue after harvest. The development of effective control agents that could keep vegetative tissue fresh without any cytotoxic effects is an especially critical issue for the fresh-cut industry. The hexapeptides selected in this study are well suited for this purpose, since they are natural substances that can be easily digested in the human body without any cytotoxicity. When the effect of KCM21 on the development of soft rot symptoms caused by PCC was evaluated in the detached leaf assay under controlled conditions, antimicrobial activity was dramatically affected by peptide concentration as well as application order (Fig. 7). Pretreatment of leaves with hexapeptide one hour before inoculation did not show any effect at any concentration. This result may be due to either rapid degradation of the hexapeptide or tissue damage that may have occurred during peptide application, which would facilitate the PCC infection process. However, significant effects were observed with the concomitant as well as the post-inoculation treatments. A dose-dependent effect was observed in the concomitant treatment (Fig. 8). The reverse correlation between concentration and the diameter of rotted tissue provides strong evidence that KCM21 was the determinant for inhibition of symptom development.

Many AMPs have been studied, but only a few are available for practical use. Despite the unique advantages of these peptides, which include a low risk of occurrence of resistant strains and environmentally friendly properties, their low stability, potential toxicity, and cost of production restrict their utility. There have been many attempts to improve the properties of AMPs or develop application systems. Lopez-Garcia et al. [19] synthesized hexapeptide PAF19 with either all D- or all L-amino acids and demonstrated that both forms have high antimicrobial activity as well as potential for disease control. The activity of the D-enantiomer was maintained over a long period of time whereas the activity of the L-enantiomer was significantly reduced after $48 \mathrm{~h}$, mainly due to proteolysis. These results suggest that using D-enantiomers may be a useful approach to improving AMP stability. An alternative approach is the use of peptidomimetics [28]. Expression of AMPs in transgenic 
plants could provide another means of conferring protection against pathogens [25]. Because of the short length of KCM21, a modification strategy such as fusion to or cleavage from a longer polypeptide should be considered. In a parallel approach, the selected AMPs could be expressed in biocontrol microorganisms to achieve enhanced bioactivity $[17,33]$. For this application to be successful, plant immunity or tolerance to the selected biocontrol agent would be a prerequisite [19].

Overall, the PS-SCL method has proven its value for the rapid selection of AMPs. This approach could be easily expanded for the control of human pathogens or for personal infection care [13]. Other advantages of this system are its flexibility and its potential to select previously unknown functional peptides in any biological system. Although intensive studies have been conducted on antibiotics, new antibiotics with different modes of action will be needed in perpetuity. PS-SCL methods can provide rich pools of antibiotics to meet this need. If these techniques are coupled with combinatorial chemistry and targeted peptide modification, more antimicrobials with improved properties could be identified.

In this study, the screening of synthetic peptide combinatorial libraries rapidly identified biologically active hexapeptides that killed a variety of phytopathogenic bacteria as well as inhibited the growth of some human pathogenic fungi. These peptides had no cytotoxic effect on mouse and human cell lines. The potential application of the very short peptide KCM21 to plant protection was evidenced in vivo.

\section{Acknowledgments}

We acknowledge Dr. Sunggi Heu (National Institute of Agricultural Science and Technology, Suwon, Korea) for the gift of the microorganisms as well as the critical review of this manuscript. We thank Dr. Jayalakshmi Krishnan for helpful comments. We thank Dr. Eunjung Roh for helping with the in vivo inoculation assay. We acknowledge Dr. Dong Soon Choi for helping with the MTT tests.

\section{REFERENCES}

1. Agrios, G. N., 2005. Plant Pathology, 4th Ed. Academic Press, London.

2. Bader, M. W., S. Sanowar, M. E. Daley, A. R. Schneider, U. Cho, W. Xu, R. E. Klevit, H. Le Moual, and S. I. Miller. 2005. Recognition of antimicrobial peptides by a bacterial sensor kinase. Cell 122: 461-472.

3. Blondelle, S. E., E. Crooks, R. Aligue, N. Agell, O. Bachs, V. Esteve, R. Tejero, B. Celda, M. T. Pastor, and E. Perez-Paya. 2000. Novel, potent calmodulin antagonists derived from an all$\mathrm{D}$ hexapeptide combinatorial library that inhibits in vivo cell proliferation: Activity and structural characterization. J. Pept. Res. 55: 148-162.

4. Blondelle, S. E. and R. A. Houghten. 1996. Novel antimicrobial compounds identified using synthetic combinatorial library technology. Trends Biotechnol. 14: 60-65.

5. Blondelle, S. E. and K. Lohner. 2000. Combinatorial libraries: A tool to design antimicrobial and antifungal peptide analogues having lytic specificities for structure-activity relationship studies. Biopolymers 55: 74-87.

6. Blondelle, S. E., E. Perez-Paya, and R. A. Houghten. 1996. Synthetic combinatorial libraries: Novel discovery strategy for identification of antimicrobial agents. Antimicrob. Agents Chemother. 40: 1067-1071.

7. Blondelle, S. E., C. Pinilla, and C. Boggiano. 2003. Synthetic combinatorial libraries as an alternative strategy for the development of novel treatments for infectious diseases. Methods Enzymol. 369: $322-344$.

8. Brogden, K. A. 2005. Antimicrobial peptides: Pore formers or metabolic inhibitors in bacteria? Nat. Rev. Microbiol. 3: 238-250.

9. Cabrefiga, J. and E. Montesinos. 2005. Analysis of Aggressiveness of Erwinia amylovora Using Disease-Dose and Time Relationships. p. 1430-1437.

10. Chen, Y., M. T. Guarnieri, A. I. Vasil, M. L. Vasil, C. T. Mant, and R. S. Hodges. 2007. Role of peptide hydrophobicity in the mechanism of action of alpha-helical antimicrobial peptides. Antimicrob. Agents Chemother. 51: 1398-1406.

11. Feng, Y., N. Huang, Q. Wu, L. Bao, and B. Y. Wang. 2005. Alpha-helical domain is essential for antimicrobial activity of high mobility group nucleosomal binding domain 2 (HMGN2). Acta Pharmacol. Sin. 26: 1087-1092.

12. Fields, G. B. and R. L. Noble. 1990. Solid phase peptide synthesis utilizing 9-fluorenylmethoxycarbonyl amino acids. Int. J. Pept. Protein Res. 35: 161-214.

13. Hancock, R. E. and H. G. Sahl. 2006. Antimicrobial and hostdefense peptides as new anti-infective therapeutic strategies. Nat. Biotechnol. 24: 1551-1557.

14. Heu, S., J. Oh, Y. Kang, S. Ryu, S. K. Cho, Y. Cho, and M. Cho. 2001. gly Gene cloning and expression and purification of glycinecin A, a bacteriocin produced by Xanthomonas campestris pv. glycines 8ra. Appl. Environ. Microbiol. 67: 4105-4110.

15. Hong, S. Y., J. E. Oh, M. Kwon, M. J. Choi, J. H. Lee, B. L. Lee, H. M. Moon, and K. H. Lee. 1998. Identification and characterization of novel antimicrobial decapeptides generated by combinatorial chemistry. Antimicrob. Agents Chemother. 42: 2534-2541.

16. Houghten, R. A. 2000. Parallel array and mixture-based synthetic combinatorial chemistry: Tools for the next millennium. Annu. Rev. Pharmacol. Toxicol. 40: 273-282.

17. Hughes, S. R., P. F. Dowd, R. E. Hector, T. Panavas, D. E. Sterner, N. Qureshi, et al. 2008. Lycotoxin-1 insecticidal peptide optimized by amino acid scanning mutagenesis and expressed as a coproduct in an ethanologenic Saccharomyces cerevisiae strain. J. Pept. Sci. 14: 1039-1050.

18. Kyte, J. and R. F. Doolittle. 1982. A simple method for displaying the hydropathic character of a protein. J. Mol. Biol. 157: $105-132$.

19. Lopez-Garcia, B., L. Gonzalez-Candelas, E. Perez-Paya, and J. F. Marcos. 2000. Identification and characterization of a 
hexapeptide with activity against phytopathogenic fungi that cause postharvest decay in fruits. Mol. Plant Microbe Interact. 13: $837-846$.

20. Lopez-Garcia, B., J. F. Marcos, C. Abad, and E. Perez-Paya. 2004. Stabilisation of mixed peptide/lipid complexes in selective antifungal hexapeptides. Biochim. Biophys. Acta 1660: 131137.

21. Lopez-Garcia, B., E. Perez-Paya, and J. F. Marcos. 2002. Identification of novel hexapeptides bioactive against phytopathogenic fungi through screening of a synthetic peptide combinatorial library. Appl. Environ. Microbiol. 68: 2453-2460.

22. Lopez-Garcia, B., W. Ubhayasekera, R. L. Gallo, and J. F. Marcos. 2007. Parallel evaluation of antimicrobial peptides derived from the synthetic PAF26 and the human LL37. Biochem. Biophys. Res. Commun. 356: 107-113.

23. Marcos, J. F., R. N. Beachy, R. A. Houghten, S. E. Blondelle, and E. Perez-Paya. 1995. Inhibition of a plant virus infection by analogs of melittin. Proc. Natl. Acad. Sci. U.S.A. 92: 1246612469.

24. Matsuzaki, K. 1999. Why and how are peptide-lipid interactions utilized for self-defense? Magainins and tachyplesins as archetypes. Biochim. Biophys. Acta 1462: 1-10.

25. Montesinos, E. 2007. Antimicrobial peptides and plant disease control. FEMS Microbiol. Lett. 270: 1-11.

26. Mosmann, T. 1983. Rapid colorimetric assay for cellular growth and survival: Application to proliferation and cytotoxicity assays. J. Immunol. Methods 65: 55-63.

27. Munoz, A., B. Lopez-Garcia, E. Perez-Paya, and J. F. Marcos. 2007. Antimicrobial properties of derivatives of the cationic tryptophan-rich hexapeptide PAF26. Biochem. Biophys. Res. Commun. 354: 172-177.

28. Ostresh, J. M., G. M. Husar, S. E. Blondelle, B. Dorner, P. A. Weber, and R. A. Houghten. 1994. "Libraries from libraries":
Chemical transformation of combinatorial libraries to extend the range and repertoire of chemical diversity. Proc. Natl. Acad. Sci. U.S.A. 91: 11138-11142.

29. Rajasekaran, K., J. W. Cary, J. M. Jaynes, and T. E. Cleveland. 2005. Disease resistance conferred by the expression of a gene encoding a synthetic peptide in transgenic cotton (Gossypium hirsutum L.) plants. Plant Biotechnol. J. 3: 545-554.

30. Reddy, K. V., R. D. Yedery, and C. Aranha. 2004. Antimicrobial peptides: Premises and promises. Int. J. Antimicrob. Agents 24: 536-547.

31. Sundin, G. W. and C. L. Bender. 1993. Ecological and genetic analysis of copper and streptomycin resistance in Pseudomonas syringae pv. syringae. Appl. Environ. Microbiol. 59: 10181024.

32. Vidaver, A. K. 2002. Uses of antimicrobials in plant agriculture. Clin. Infect. Dis. 34 Suppl 3: S107-S110.

33. Wan, Y. K., S. P. Tian, and G. Z. Qin. 2003. Enhancement of biocontrol activity of yeasts by adding sodium bicarbonate or ammonium molybdate to control postharvest disease of jujube fruits. Lett. Appl. Microbiol. 37: 249-253.

34. Yeaman, M. R. and N. Y. Yount. 2003. Mechanisms of antimicrobial peptide action and resistance. Pharmacol. Rev. 55: 27-55.

35. Yedery, R. D. and K. V. Reddy. 2005. Antimicrobial peptides as microbicidal contraceptives: Prophecies for prophylactics - a mini review. Eur. J. Contracept. Reprod. Health Care 10: 3242.

36. Zasloff, M. 2002. Antimicrobial peptides of multicellular organisms. Nature 415: 389-395.

37. Zhao, C., T. Nguyen, L. M. Boo, T. Hong, C. Espiritu, D. Orlov, W. Wang, A. Waring, and R. I. Lehrer. 2001. RL-37, an alpha-helical antimicrobial peptide of the rhesus monkey. Antimicrob. Agents Chemother. 45: 2695-2702. 